\title{
SYNTHESIS AND APPLICATION OF NATURAL DYE SENSITIZD CdS THIN FILMS AS PHOTOANODE FOR DSSC
}

\author{
N. Goswami ${ }^{1}$, P. K. Gogoi ${ }^{2}$ \\ ${ }^{1}$ Assistant Professor, Department of Chemistry, Sibsagar College, Joysagar - 785665, India \\ ${ }^{2}$ Professor, Centre for Nanoscience and Composite Material, Department of Chemistry, Dibrugarh University, \\ Dibrugarh-786004, India
}

\begin{abstract}
Natural dyes obtained from plants, vegetables and fruits are widely studied and tested as low cost sensitizer for dye sensitized solar cell (DSSC) in order to replace the rare and expensive inorganic and organic sensitizers. Although, many works have been done using $\mathrm{TiO}_{2}, \mathrm{ZrO}_{2}, \mathrm{ZnO}$ etc. as the nanoporous semiconductor, little importance was given to the use of CdS thin film as a cost effective alternative. In the present study CdS thin films were synthesized by chemical bath deposition (CBD) technique and its optical, structural and morphological properties were investigated by XRD, SEM and UV-Vis absorption spectroscopy. The as synthesized films were found to be nanoporous in nature and are favorable for adsorbing the dyes on to its surface. Two natural dyes extracted from locally available plant leaves namely lawsonia inermis linn and caesalpinia pulcherrima were then adsorbed on the as synthesized CdS thin films for the formation of the working electrode for application in DSSC. The interaction between the nanoporous CdS thin films and the natural dyes were investigated through UV-Vis absorption spectroscopy with an aim to fabricate working electrode for application in DSSC.
\end{abstract}

Keywords: DSSC, thin film, CdS, natural dyes

\section{INTRODUCTION}

Dye-sensitized solar cell (DSSC), being the third generation solar cell developed by O'Regan and Gratzel in 1991 [1] have been receiving substantial interest due to its low cost, environment friendliness and overall simplicity as it works by converting inexpensive photon from solar energy to electrical energy, based on sensitization of wide band gap semiconductors [2].

Generally, transition metal coordination compounds such as $\mathrm{Ru}$ - polypyridyl complexes and pure organic dyes are used as sensitizer due their good light harvesting property and stability[3-8]. However, application of these types of sensitizers also faced problems regarding complicated synthetic routes, low efficiency and most importantly use of environmentally non-benign chemicals.[9]. Thus, as a green alternative, natural dyes obtained from natural pigments having similar characteristic are used with the advantages such as their availability, environmental friendliness and low cost [10-16].

The efficiency of a cell also depends upon the anchoring of the dye on the mesoporous semiconductor. Though, a lot of work has been done using $\mathrm{TiO}_{2}$ as wide band gap semiconductor due to its high efficiency [17], but there is a good prospect of using other semiconductors such as $\mathrm{ZnO}$, $\mathrm{ZnS}$, and CdS which have a band gap comparable with $\mathrm{TiO}_{2}$. $\mathrm{CdS}(2.42 \mathrm{eV})$ is such a wide band gap semiconductors from II-VI group which may be an attractive candidate for application in solar cell due to its high absorption coefficient and considerable energy conversion efficiency.[1820].
Thin films of CdS can be obtained by number of growth techniques such as chemical bath deposition (CBD), electrodeposition, thermal evaporation , screen printing , photochemical deposition, sputtering, and spray pyrolysis [21-27]. However, CBD being a simple and low cost technique is used for large scale industrial applications and it also helps to achieve high quality films by controlled chemical reaction with minimum wastage of material following a greener perspective. Although, there are a number of reports on the optical, electrical and photoelectric properties of CdS thin films, but yet not enough work has been reported on the adsorption of natural dyes on $\mathrm{CdS}$ thin film [21] .

In the present study, CdS thin films were deposited on glass substrates from an ammonia bath by continuous dip coating technique for different deposition times. The optical, structural and morphological properties of the films were investigated by UV-Vis absorption, X-ray diffraction (XRD), and scanning electron microscopy (SEM). Two natural dyes extracted from locally available plant leaves namely lawsonia inermis linn and caesalpinia pulcherrima were then adsorbed on the as synthesized CdS thin films for the formation of the photoanode (working electrode) for application in DSSC. The interaction between the CdS thin films and the natural dyes were investigated through UV-Vis absorption spectroscopy with an aim to evaluate the optimised photoanode with better anchorage of the dyes. 


\section{EXPERIMENTAL}

\subsection{Materials}

All reagents, viz. Cadmium acetate $\left[\left(\mathrm{CH}_{3} \mathrm{COO}\right)_{2} \mathrm{Cd} \cdot 2 \mathrm{H}_{2} \mathrm{O}\right]$, thiourea, $\left[\mathrm{CS}\left(\mathrm{NH}_{2}\right)_{2}\right]$, ammonia, ethanol etc. were of analytical grade obtained from Merk(India) Ltd. Deionised water was used throughout the experiments.

\subsection{Apparatus}

The crystallographic structures of the films were analyzed with a Rigaku Ultima -IV X-ray diffractometer using $\mathrm{Cu}-$ $\mathrm{K} \alpha$ radiations operated at $40 \mathrm{kV}$ and $40 \mathrm{~mA}$. For optical studies, optical absorbance spectra in the vicinity of absorption edge were recorded using Perkin-Elmer spectrophotometer. Surface morphology and particle size was examined by LEO 1430VP Scanning Electron Microscope.

\subsubsection{Synthesis of CdS Thin Films}

$\mathrm{CdS}$ thin films were deposited on glass substrates by CBD technique using cadmium acetate $\left[\left(\mathrm{CH}_{3} \mathrm{COO}\right)_{2} \mathrm{Cd} .2 \mathrm{H}_{2} \mathrm{O}\right]$ as $\mathrm{Cd}^{2+}$ ion source and thiourea $\left[\mathrm{CS}\left(\mathrm{NH}_{2}\right)_{2}\right]$ as $\mathrm{S}^{2-}$ ion source with cadmium to sulphur $(\mathrm{Cd}: \mathrm{S})$ molar ratio $3: 5$. The synthetic technique used in the present study is from the literature, but with a little modification of the process by varying the deposition time interval. In a typical reaction, equal volume of $0.6 \mathrm{M}$ cadmium acetate and $1 \mathrm{M}$ thiourea solutions were taken in a beaker, stirred for 15- 20 minutes and then the reaction mixture is heated at $60^{\circ} \mathrm{C}$ for 3 hours. To these solutions $\mathrm{NH}_{3}$ was added slowly and $\mathrm{pH}$ was adjusted at 9.5. The solutions were then stirred for 10-15 minutes and transferred into a bath containing chemically clean glass substrates. The substrates were held vertically with the help of a substrate holder and temperature of the bath was maintained at $60^{\circ} \mathrm{C}$. A set of three films A, B and $\mathrm{C}$ were obtained by changing the deposition time from 1 to 2 hour. After deposition, the substrates were removed from the chemical bath and thoroughly washed in doubly distilled water.

\subsubsection{Reaction scheme for CdS Thin Film Synthesis:}

In aqueous solution, cadmium acetate dissociates to give $\mathrm{Cd}^{2+}$ ions. Hydrolysis of ammonia in water gives $\mathrm{OH}^{-}$ions, which forms complex $\quad\left[\mathrm{Cd}\left(\mathrm{NH}_{3}\right)_{4}\right]^{2+}$. Thiourea in alkaline medium acts as an $\mathrm{S}^{2-}$ ion source. In short, the reaction for the process is

$$
\begin{aligned}
{\left[\mathrm{Cd}\left(\mathrm{NH}_{3}\right)_{4}\right]^{2+}+\mathrm{SC}\left(\mathrm{NH}_{2}\right)_{2} } & +2 \mathrm{OH}^{-} \rightarrow \mathrm{CdS} \downarrow+4 \mathrm{NH}_{3}+\mathrm{CH}_{2} \mathrm{~N}_{2} \\
& +2 \mathrm{H}_{2} \mathrm{O}
\end{aligned}
$$

\subsection{Extractions of Natural Dyes}

Two dyes were extracted from locally available plant leaves of lawsonia inermis linn and flowers of caesalpinia pulcherrima using water as solvent. For aqueous extraction of the dyes, $100 \mathrm{gm}$ of finely crushed fresh leaves of lawsonia inermis linn and flowers of caesalpinia pulcherrima were transferred into two conical flasks containing $100 \mathrm{ml}$ of deionised water and then boiled for 30 minutes at $100^{\circ} \mathrm{C}$. The extracts were kept in dark for 24 hour and then filtered with a whatman 40 no. filter paper.

All the filtrates were collected and stored in an air tight bottle at $0^{\circ} \mathrm{C}$ until the $\mathrm{CdS}$ films are dipped into the dye solutions for the anchorage of the dye on the semiconducting surface.

\section{RESULTS AND DISCUSSION}

\subsection{Structural and Morphological Studies:}

XRD patterns of the CdS thin films deposited by CBD technique at a bath $\mathrm{pH}=9.5$, but for different deposition times (1h to $2 \mathrm{~h}$ ) are shown in Fig 1(a).

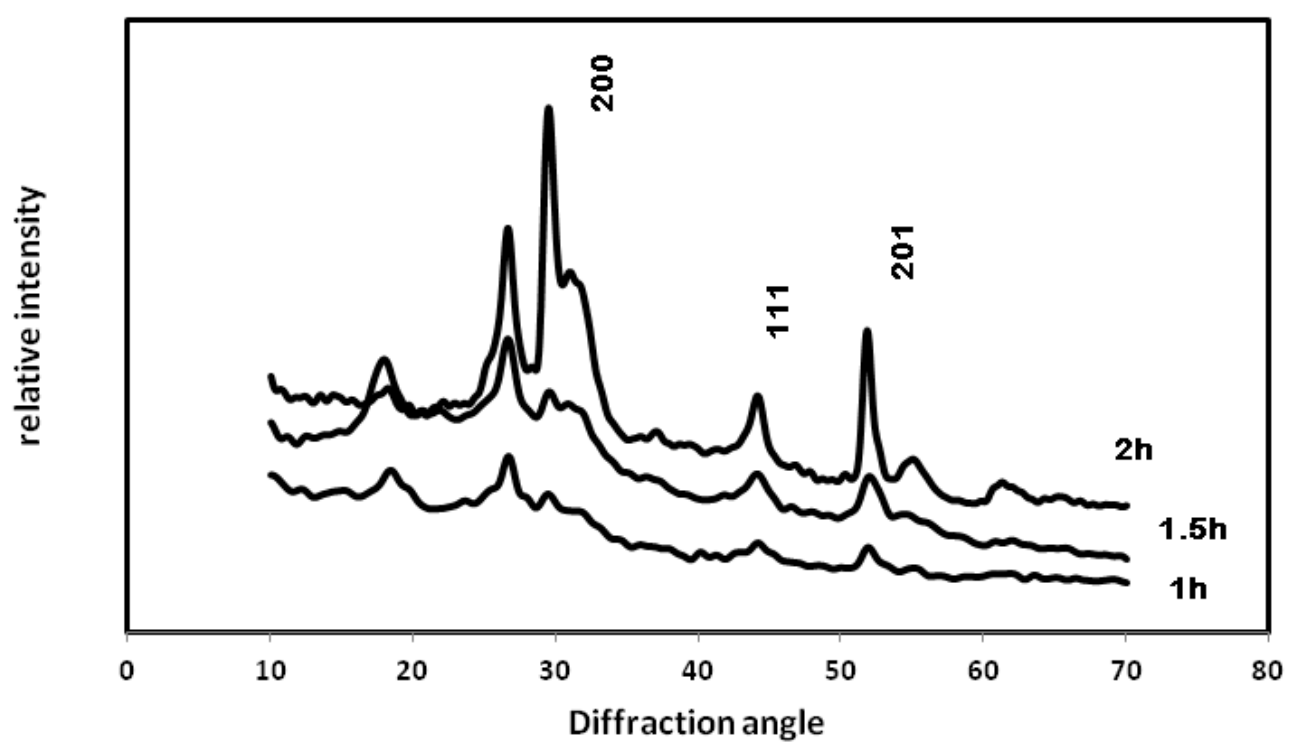

Fig. 1 (a): XRD of CdS thin films at 1h, 1.5h and $2 \mathrm{~h}$ time 
The XRD analysis reveals that the as synthesized films are polycrystalline in nature with a preferential orientation along (200) direction. The peaks were detected at $2 \theta=26.4,29.4$, 43.7 and 51.7 which can be ascribed due to (002), (200), (110) and (201) reflection planes of the hexagonal CdS structure, respectively [27]. The XRD spectra reveals that the film deposited at a time interval of $2 \mathrm{~h}$ exhibits better crystalline nature in comparison to the films prepared at deposition intervals of $1 \mathrm{~h}$ and $1.5 \mathrm{~h}$

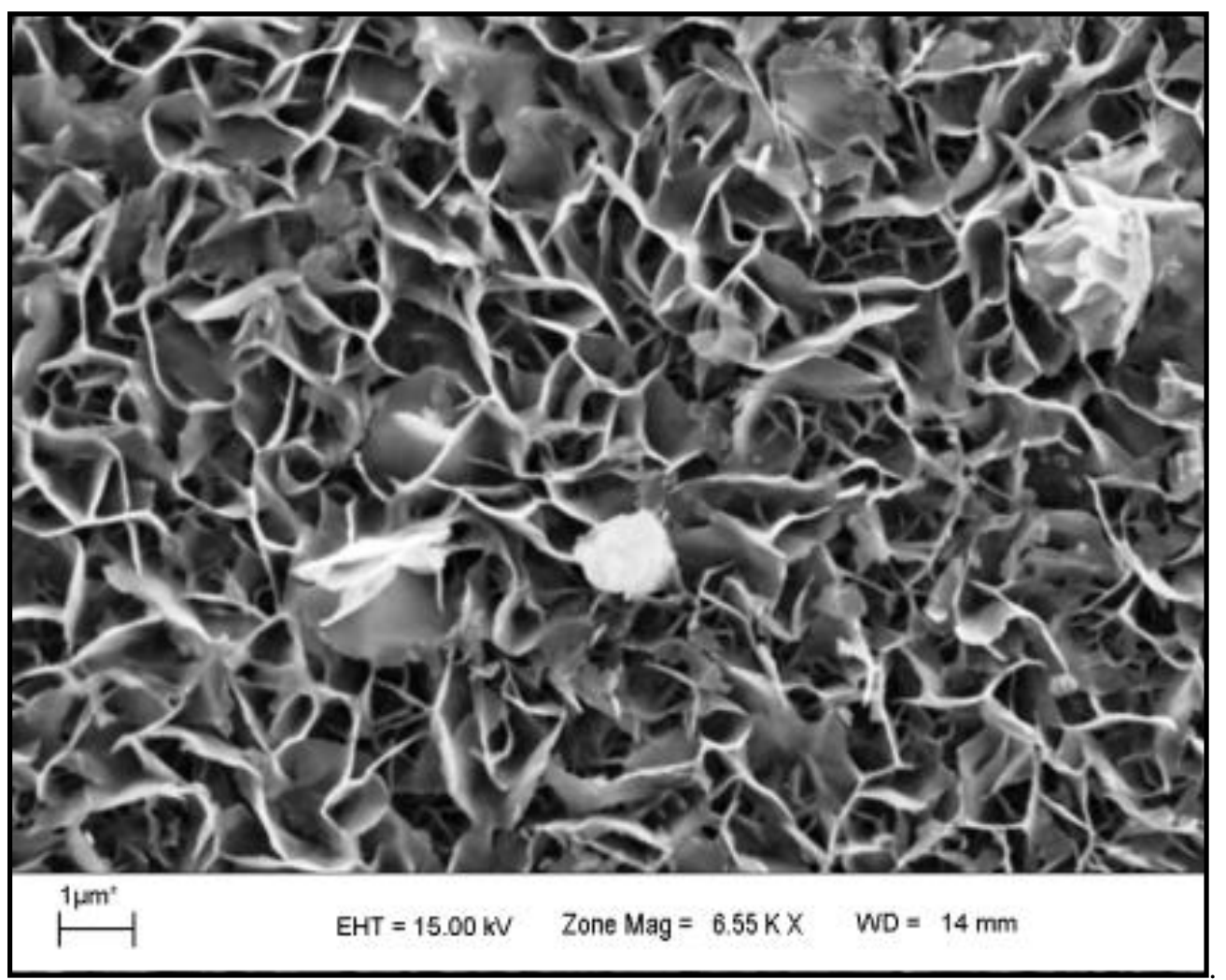

Fig. 1(b) SEM of CdS thin film (2h)

The SEM micrograph of the CdS thin film prepared at $2 \mathrm{~h}$ of deposition time is presented in Fig. 1 (b). The surface of the film is found to be mesoporous in nature and thus suitable for adsorbing the dye on its surface.

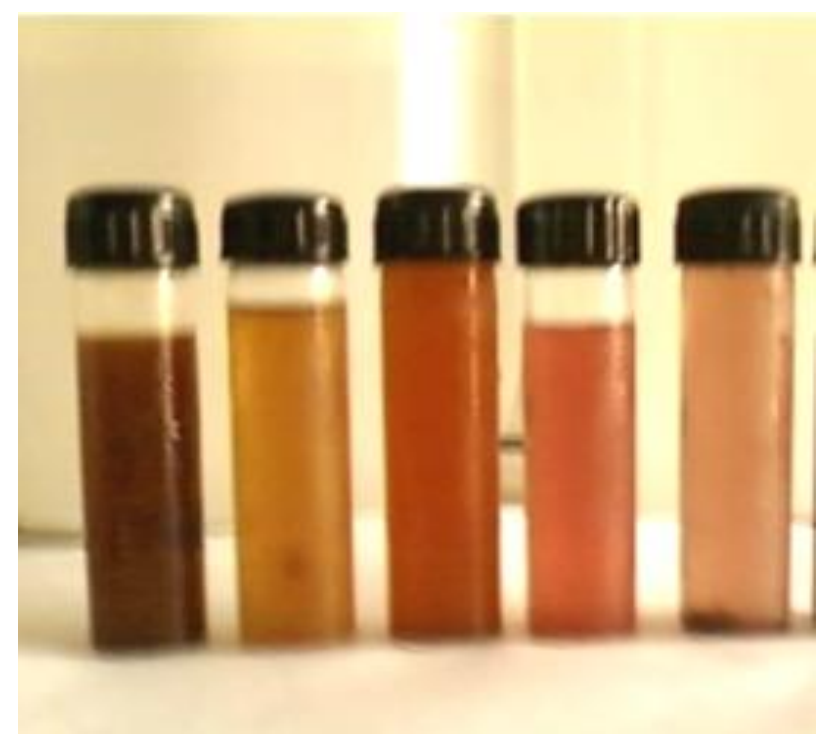

Fig. 1 (c): Sample of extracted dyes

\subsection{Optical Studies:}

The figure 2(a) shows the electronic absorption spectra of extracts obtained from lawsonia inermis linn and caesalpinia pulcherrima .It was found that the absorption peak of the dye extracted from lawsonia inermis linn is about $470 \mathrm{~nm}$ while that obtained from caesalpinia pulcherrima is at about $500 \mathrm{~nm}$ with lower intensity. The difference in the absorption characteristics is due to the different type of composition and colours of the extracts. The active constituents of the lawsonia inermis linn is lawsone $(0.5-1.0 \%)$. Other constituents are $5-10 \%$ gallic acid, white resin, tannin and xanthones 


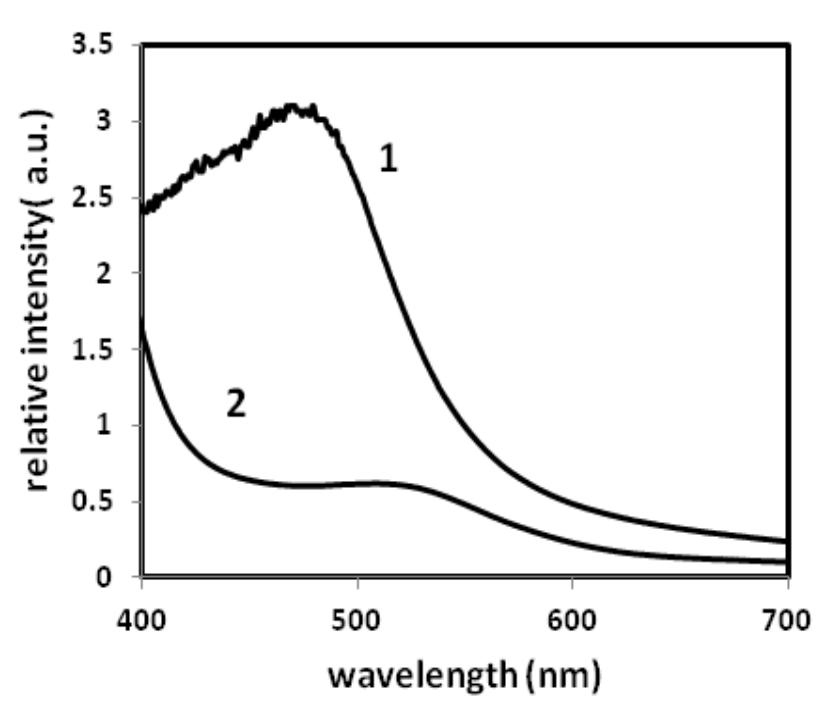

Fig.2(a) : UV-Vis absorption spectra of aqueous extract of "lawsonia inermis linn" at (1) and flowers of caesalpinia pulcherrima (2)

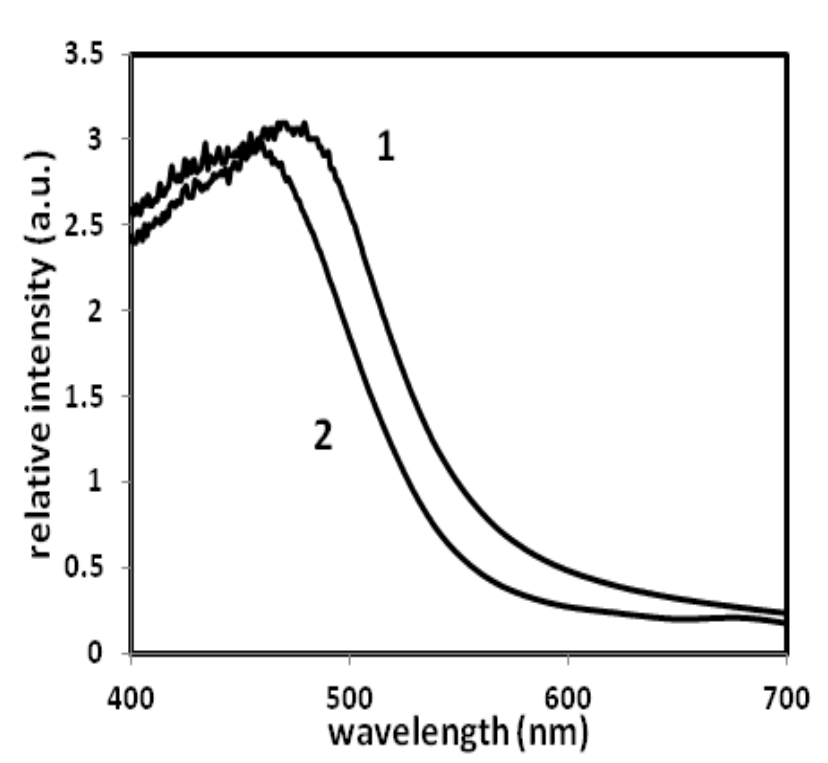

Fig. 2 (b) : Comparison of UV-Vis spectra of the extracts of lawsonia inermis linn 1. fresh 2. aged for two months

etc. The 'Lawsone' is principally responsible for the colorant property of the leaves. On the other hand, appearance of pink colour reveals the presence of some type of anthroquinons in caesalpinia pulcherrima flowers which is one of the responsible elements to become a dye sensitizer.

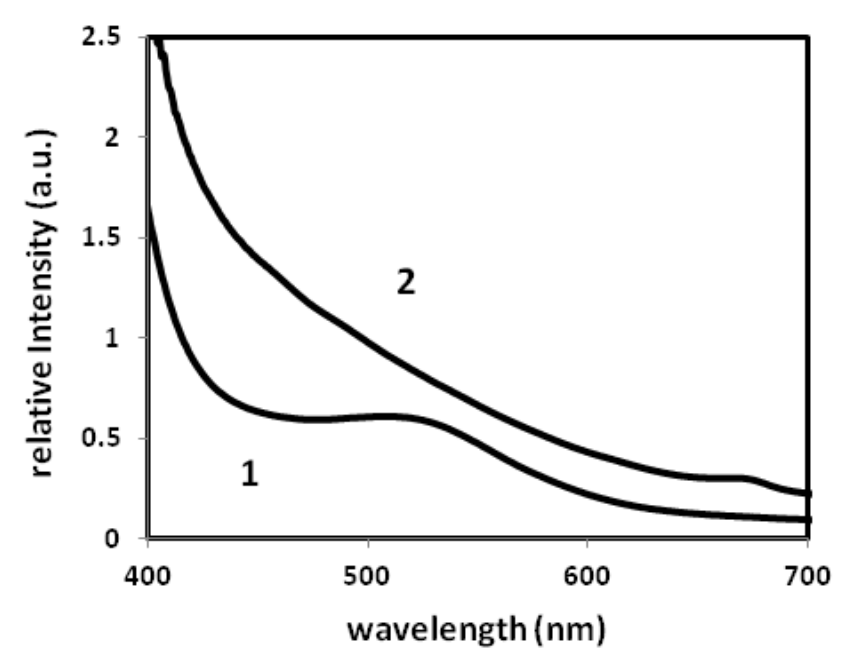

Fig. 2 (c): Comparison of UV-Vis spectra of the extracts of caesalpinia pulcherrima 1 . fresh 2 . aged for two months

It is also observed from the electronic spectra recorded two months back, ( as in Fig 2(b) and 2(c)), that the rate of degradation of the dye obtained from caesalpinia pulcherrima extract is more than that obtained from lawsonia inermis linn extract.

Thus, in terms of greater absorption and stability of the dye, lawsonia inermis linn leaves are more preferred for anchorage with the semiconductor $\mathrm{CdS}$ than the flowers of caesalpinia pulcherrima .

\subsection{Fabrication of Photoanode}

For the fabrication of the photoanode, the optimized dye extract of lawsonia inermis linn were adsorbed onto the surfaces of the as synthesized CdS thin films by continuous dip coating technique. The films were withdrawn after 24 hour dip time, washed in distilled water and dried in an oven at $40^{\circ} \mathrm{C}$ for $5 \mathrm{~h}$. The color of the film was found to change from bright yellow to red indicating the anchorage of the dyes on the surface of CdS thin films.

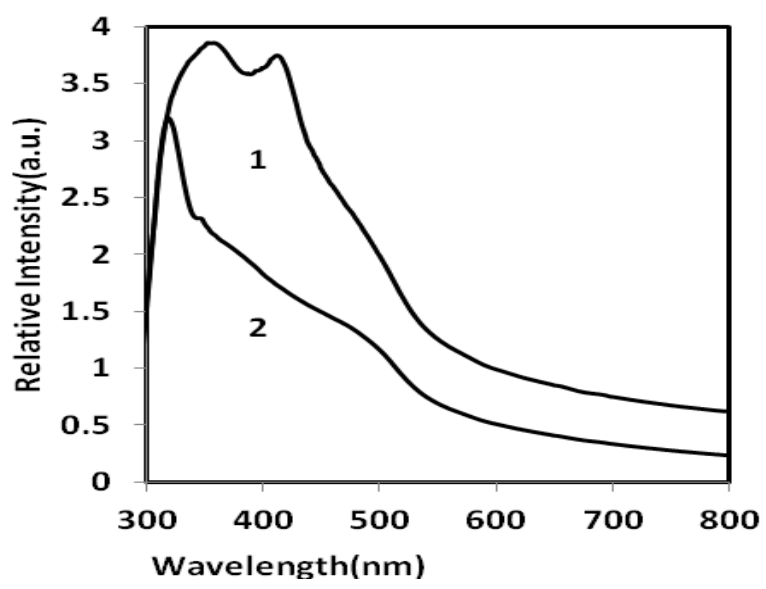

Fig. 3(a) : UV- Vis spectra of CdS (1h) unsoaked(1) and $\operatorname{soaked}(2)$ 


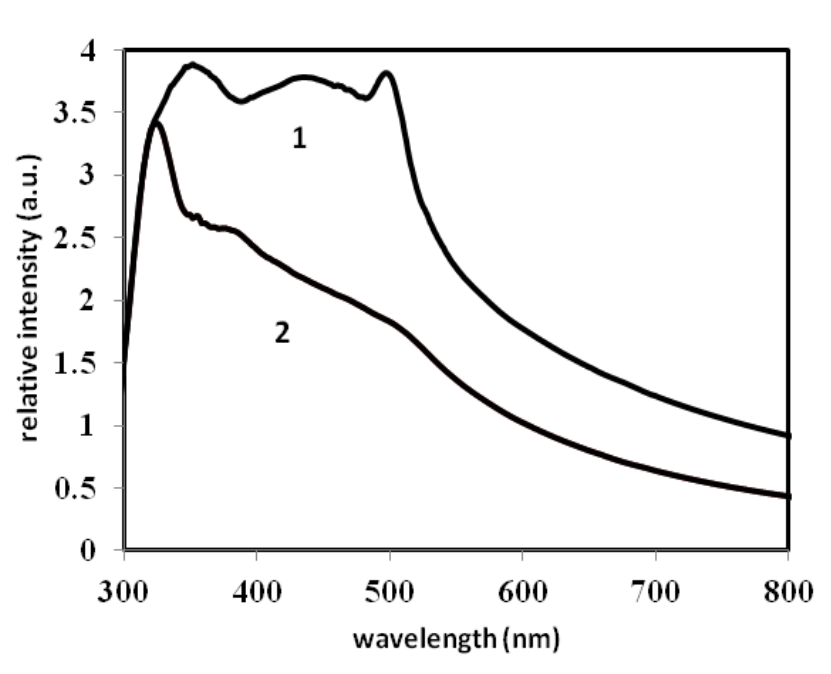

Fig: 3(b) : UV- Vis spectra of CdS (2h) unsoaked(2) and soaked(1)

A comparison of the UV-visible absorption spectra of the unsoaked and dye soaked CdS thin films prepared at $1 \mathrm{hr}$ to $2 \mathrm{hr}$ of deposition times are presented in Fig 3(a) and Fig 3(b).

From the spectra it was observed that the dye adsorbed films showed increased absorption in comparison to its unsoaked counterpart which is an indication of the good anchorage of the dyes on the surface of the CdS thin films. However, owing to the good crystalline as well as mesoporous nature and anchoring behaviour, the film prepared at $2 \mathrm{~h}$ of deposition times is found to be more suitable as photoanode for application in DSSC.

\section{CONCLUSION}

Thin films of CdS have been prepared by CBD technique varying the deposition times from $1 \mathrm{~h}$ to $2 \mathrm{~h}$. The as synthesized CdS thin films were found to be polycrystalline and mesoporous in nature thus being suitable for application as photoanode in DSSC. Two natural dyes were extracted and the optimized dye was anchored with the as synthesized films. A comparison of the absorption spectra of the unsoaked and the dye sensitized films indicates a good anchorage between the dye and the CdS thin films making them a suitable electrode for DSSC.

\section{ACKNOWLEDGEMENTS}

The authors acknowledge CIF, Indian Institute of technology, Guwahati for recording SEM and XRD and UGC, DST for financial support.

\section{REFERENCES}

[1] O'Regan B,Grätzel, M,A low-cost, high-efficiency solar cell based on dye sensitized colloidal $\mathrm{TiO}_{2}$ films, Nature ,353 (1991) ,737 - 740 .

[2] Bisquert, J. García-Cañadas, I. Mora- Seró and E. Palomares,Comparative analysis of photovoltaic principles governing dye-sensitized solar cells and pn junctions, Journal Spin Use 6 (2003) ,5215.
[3] Gratzel. M., Dye-sensitized solar cell, Journal of Photochemistry \& Photobiology C 4 (2003), 145.

[4] S. Hao etal, " Natural dyes as photosensitizers for dye sensitized solar cell“" Journal Solar energy , 80 (2006), 209-214

[5] Shekhar N and Gehlot Y, Vishal, metal complex dyes for dye sensitized solar cell, General article , Resonance, Sep' 2010

[6] Hon Minh Ngyen etal, Improved performance of dye sensitized solar cell by tuning the properties of $\mathrm{Ru}$ complex conjugated bipyridines ligands, Adv. Nat. Sci. Nanosci. Nanotech. 1 (2010) (025001) 6

[7] K. Pattarith et al,Synthesis of metal free organic dye for dye sensitized solar cell, Journal of Korean Chem Society, 2011, vol- 55, No 2

[8] Hara. K. etal, Dye-sensitized nanocrystalline TiO2 solar cells based on novel coumarin dyes, Solar energy materials and solar cells , (2003), 77, 89

[9] Y. Amao, T. Komori, Bio-photovoltaic conversion device using chlorine-e6 derived from chlorophyll from Spirulina adsorbed on a nanocrystalline $\mathrm{TiO}_{2}$ film electrode. Biosensors Bioelectron. 19 (2004) 843.

[10] Hao S. Hao, J. Wu, Y. Huang, J. Lin, "Natural dyes as photosensitizers for dye-sensitized solar cell, Sol. Energy 80 (2006) 209-214.

[11] Polo, A.S. . Murakami N.Y, Blue sensitizers for solar cells: natural dyes from Calafate and Jaboticaba, Sol. Energ. Mat. Sol. Cell 90 (2006) 1936-1944.

[12] P.M. Sirimanne, M.K.I. Senevirathna, E.V.A. Premalal, P.K.D.D.P. Pitigala, V. Sivakumar, K. Tennakone, Utilization of natural pigment extracted from pomegranate fruits as sensitizer in solid-state solar cells, J. Photochem. Photobiol. A 177 (2006) 324-327

[13] Tennakone, K., Kumarasinghe, A.R., Kumara, G.R.R.A., Wijayantha, K.G.U. Sirimanne , P.M. ,Nanoporous $\mathrm{TiO}_{2}$ photoanode sensitized with the flower pigment cyaniding, J. Photochem. Photobiol. A 108 (1997) 193-195

[14] Roy, M.S, Balraju P, Kumar, M. Sharma, G.D, Dyesensitized solar cell based on Rose Bengal dye and nanocrystalline TiO2, Sol. Energ. Mat. Sol. C 92 (2008) 909-913.

[15] J.M.R.C. Fernando, G.K.R. Senadeera,Natural anthocyanins as photo sensitizers for dye sensitized solar devices , Curr. Sci,. 95 (2008) 663-666.

[16] R. N. Bhattacharya, M. A. Contreras and G. Teeter, 18.5\% Copper Indium Gallium Diselenide (CIGS) Device Using Single-Layer, chemical-bath-deposited $\mathrm{ZnS}(\mathrm{O}, \mathrm{OH})$, J. Appl. Phys. 43 (2004)

[17] Xiaobo Chen, and Samuel S. Mao, Titanium Dioxide Nanomaterials: Synthesis, Properties, Modifications, and Applications, Chem. Rev, 2007, 107 (7)

[18] Feitosa, A.V et al. A new route for preparing CdS thin films by chemical bath deposition using EDTA as ligand, Brazilian Journal of Physics, vol. 34, 2B (2004). 
[19] Pawar, S.H, .Bhosale, C.H, Electrochemical bath deposition technique: Deposition of CdS thin films, Bull. Matter. Sci., 8(3), 419 (1986).

[20] Salazar, Y.A et al. Physical properties of CdS/ITO thin films growth by CBD technique with substrate oscillating agitation, Brazilian Journal of Physics, 36(3B), (2006).

[21] Saikia, D,Gogoi, P.K., Saikia, P.K., Structural and optical properties of nanostructured CdS thin films deposited at different preparative conditions, Chalcogenide Letters, vol.7, No. 5, (2010),317-324

[22] Kumar, V. Sharma, M..K, GAUR, J. SHARMA,T. POLYCRYSTALLINE ZnS THIN FILMS BY SCREEN PRINTING METHODAND ITS CHARACTERIZATION, Chalcogenide Letters Vol. 5, No. 11, (2008), 289 - 295

[23] R. Kobayashi, N. Sato, M. Ichimura, E. Arai,PHOTOCHEMICAL DEPOSITION OF $\mathrm{ZnS}$ THIN FILMS FROM $\mathrm{C}_{4} \mathrm{H}_{4} \mathrm{KNaO}_{6}$-ADDED SOLUTIONS, Journal of Optoelectronics and Advanced Materials Vol. 5, No. 4, (2003), 893 - 898

[24] J. Aguilar- Hernandez etal Photoluminescence and structural properties of cadmium sulphide thin films grown by different techniques, Semicond. Sci. Technol. 18 (2003) 111.

[25] I. K. Battisha, H. H. Afify, G. Abd El Fattah, Y. Badr, Raman and photoluminescence studies of pure and Sn-enriched thin films of CdS prepared by spray pyrolysis, Fizika A 11 (2002) 31.

[26] A.V. Feitosa, et al. A new route for preparing CdS thin films by chemical bath deposition using EDTA as ligand", Brazilian Journal of Physics, vol. 34, 2B (2004).

[27] A. Ates, M.A. Yildrim, M. Kundakci and M. Yildrim, "Investigation of optical and structural properties of CdS Thin Films, Chinese Journal of Physics, (2-I), 135 (2007).

\section{BIOGRAPHIES}

Ms. N. Goswami , M.Sc. M.Phil. , Asst. Prof , Sibsagar College, Assam. She did her M.Sc, from University of Delhi in 2003 and M.Phil. from Dibrugarh University in 2006. She is presently registered as a research scholar in Dibrugarh University pursuing research in the field of dye sensitized solar cell. So far, she has presented a no. of papers in many national and international conferences and published a few papers in proceedings and journals. Her area of interests are Solar energy, Dye sensitized solar cell, Green Chemistry and nanomaterial .

Professor P. K. Gogoi did his M.Sc. from Dibrugarh University in 1975 and Ph. D. from I.I.T. Bombay in 1981 and then went London for further research. His research interest are Coordination Chemistry, inorganic materials, Nanomaterials , Corrosion Science, Petroleum Reservoir Engineering, theoretical Chemistry etc.So far he has published 81 research papers in various national and international journals 